\title{
Characterization and thermal expansion of $\mathrm{Sr}_{2} \mathrm{Fe}_{x} \mathrm{Mo}_{2-x} \mathrm{O}_{6}$ double perovskites
}

\author{
Y MARKANDEYA $^{1}$ (D), Y SURESH REDDY ${ }^{2}$, SHASHIDHAR BALE ${ }^{1}$, \\ C VISHNUVARDHAN REDDY ${ }^{2}$ and G BHIKSHAMAIAH ${ }^{2, *}$ \\ ${ }^{1}$ Department of Physics, Nizam College, Osmania University, Hyderabad 500 001, India \\ ${ }^{2}$ Department of Physics, Osmania University, Hyderabad 500 007, India
}

MS received 23 February 2015; accepted 25 June 2015

\begin{abstract}
Double perovskite oxides $\mathrm{Sr}_{2} \mathrm{Fe}_{x} \mathrm{Mo}_{-x} \mathrm{O}_{6}(x=0.8,1.0,1.2,1.3$ and 1.4) (SFMO) of different compositions were prepared by sol-gel growth followed by annealing under reducing atmosphere conditions of $\mathrm{H}_{2} / \mathrm{Ar}$ flow. X-ray powder diffraction studies revealed that the crystal structure of the samples changes from tetragonal to cubic at around $x=1.2$. Lattice parameters and unit cell volume of these samples found to decrease with the increase in Fe content. The characteristics absorption bands observed in the range $400-1000 \mathrm{~cm}^{-1}$ of Fourier transform infrared spectra indicate the presence of $\mathrm{FeO}_{6}$ and $\mathrm{MoO}_{6}$ octahedra and confirm the formation of double perovskite phase. The value of $g \sim 2.00$ obtained from electron spin resonance studies indicates that Fe is in $3+$ ionic state in the SFMO samples. Dilatometric studies of these samples reveal that the average value of coefficient of thermal expansion $(\bar{\alpha})$ increases with the increase in temperature or Fe content in SFMO samples. The low value of coefficient of thermal expansion $1.31 \times 10^{-6}{ }^{\circ} \mathrm{C}^{-1}$ obtained for $\mathrm{Sr}_{2} \mathrm{Fe}_{0.8} \mathrm{Mo}_{1.2} \mathrm{O}_{6}$ in the present study in the temperature range of 40$100^{\circ} \mathrm{C}$ makes it useful as anode material in fuel cells. The coefficient of thermal expansion $(\bar{\alpha})$ and the unit cell volume $(V)$ of SFMO samples vary inversely with composition in agreement with Grüneisen relation.
\end{abstract}

Keywords. Sol-gel chemistry; oxides; crystal structure; electron microscopy; thermal expansion.

\section{Introduction}

Double perovskite materials have gained lot of research interest in recent years owing to their significant applications such as anode materials in fuel cells, magnetic storage devices. Especially double perovskite oxide $\mathrm{Sr}_{2} \mathrm{FeMoO}_{6}$ doped with several elements were extensively studied for magnetoresistance and magnetization. ${ }^{1-17}$ This compound crystallizes in tetragonal lattice with space group $\mathrm{I} 4 / \mathrm{mmm} .^{1}$ The structure of $\mathrm{Sr}_{2} \mathrm{FeMoO}_{6}$ can be viewed as a regular arrangement of corner-sharing $\mathrm{FeO}_{6}$ and $\mathrm{MoO}_{6}$ octahedra, alternating along the three directions of the crystal with the Sr cations occupying the voids in between the octahedra. ${ }^{1,3}$ Thermal expansion studies give information regarding the expansion coefficient of a material and its applicability as sealants. However, there is no work reported on thermal expansion studies on these materials except on stoichiometric $\mathrm{A}_{2} \mathrm{FeMoO}_{6}(\mathrm{~A}=\mathrm{Sr}, \mathrm{Ba}, \mathrm{Ca}){ }^{11}$ In addition, $\mathrm{Fe}$ and $\mathrm{Mo}$ are d-block elements and their ions are of almost same size. In view of this, the authors have taken up synthesis of $\mathrm{Sr}_{2} \mathrm{Fe}_{x} \mathrm{Mo}_{2-x} \mathrm{O}_{6}$ by interchanging $\mathrm{Fe}$ and Mo content in their sites with an objective to characterize them using X-ray diffraction (XRD), scanning electron microscopy (SEM), Fourier transform infrared (FTIR) spectroscopy, electron

\footnotetext{
*Author for correspondence (gbhyd08@gmail.com)
}

spin resonance (ESR) and study thermal expansion at elevated temperatures.

\section{Experimental}

Different composition of $\mathrm{Sr}_{2} \mathrm{Fe}_{x} \mathrm{Mo}_{2-x} \mathrm{O}_{6}(x=0.8,1.0,1.2$, 1.3 and 1.4) (SFMO) powders were synthesized by the solgel method using AR grade $\mathrm{Sr}\left(\mathrm{NO}_{3}\right)_{2}, \mathrm{Fe}\left(\mathrm{NO}_{3}\right)_{3} \cdot 9 \mathrm{H}_{2} \mathrm{O}$ and $\mathrm{H}_{2} \mathrm{MoO}_{4}$. The details of the synthesis of the SFMO powders are given in earlier publications ${ }^{7,8}$ from this laboratory. The powders of SFMO were pressed into pellets of dimensions $25 \mathrm{~mm} \times 6 \mathrm{~mm} \times 6 \mathrm{~mm}$ using a dies under a pressure of $5 \mathrm{t} \mathrm{m}^{-2}$. These pellets were sintered at $1200^{\circ} \mathrm{C}$ for 6 $\mathrm{h}$ and then heated at $1000^{\circ} \mathrm{C}$ in a stream mixture of gas $\left(10 \% \mathrm{H}_{2}+90 \% \mathrm{Ar}\right)$ for $3 \mathrm{~h}$ for reducing $\mathrm{Mo}^{6+}$ into $\mathrm{Mo}^{5+}$. These pellets were subjected to XRD studies using Philips PW 1830 diffractometer with $\mathrm{Cu} \mathrm{K} \alpha$ radiation $(40 \mathrm{kV} \times$ $25 \mathrm{~mA}$ ) to confirm the crystal structure. Surface morphology of the samples was found using the SEM (Model no. Joel JSM-5600) with combined microanalyzer. FTIR spectra of the samples were recorded on Bruker Tensor 27 DTGS TEC detector spectrophotometer in the wavenumber range of $400-1000 \mathrm{~cm}^{-1}$ by the $\mathrm{KBr}$ pellet method. ESR spectra were recorded at room temperature using a JOEL-1X-ESR spectrometer that works in X-band frequency range $(8-12.5 \mathrm{GHz})$ with $100 \mathrm{kHz}$ field modulation. Thermal expansion measurements were performed using Netzsch 402 PC dilatometer in the temperature range of $40-400^{\circ} \mathrm{C}$ during heating cycle. 


\section{Result and discussion}

\subsection{Characterization}

XRD patterns of various compositions of SFMO samples are shown in figure 1 . These patterns reveal that the observed diffraction profiles belong to double perovskite structure of $\mathrm{Sr}_{2} \mathrm{FeMoO}_{6} \cdot{ }^{4-6}$ All the profiles of SFMO are indexed and found to be in single phase. The lattice parameters of SFMO were evaluated by Cohen's least square method using $(h k l)$ values and Bragg's angles with a suitable computer program. It has been found that SFMO crystallizes in tetragonal lattice (space group $\mathrm{I} 4 / \mathrm{mmm}$ ) for $0.8 \leq x \leq 1.2$ and cubic lattice (space group $\mathrm{Fm} \overline{3} \mathrm{~m}$ ) for $x>1.2$. The values of lattice parameters ' $a$ ' and ' $c$ ' of SFMO are given in table 1 . The unit cell volume $V=a^{3}$ for cubic and $2 a^{2} c$ for tetragonal structure were calculated using lattice parameters and are included in table 1. It is found that the value of ' $a$ ', ' $c$ ' and $V$ decreases with the increase of Fe content in both tetragonal and cubic phase. Since the ionic radius of $\mathrm{Fe}^{3+}(0.645 \AA)$ is larger than that of $\mathrm{Mo}^{5+}(0.61 \AA)$, the decrease in ' $a$ ', ' $c$ ' and $V$ might be attributed to cation or oxygen vacancies or

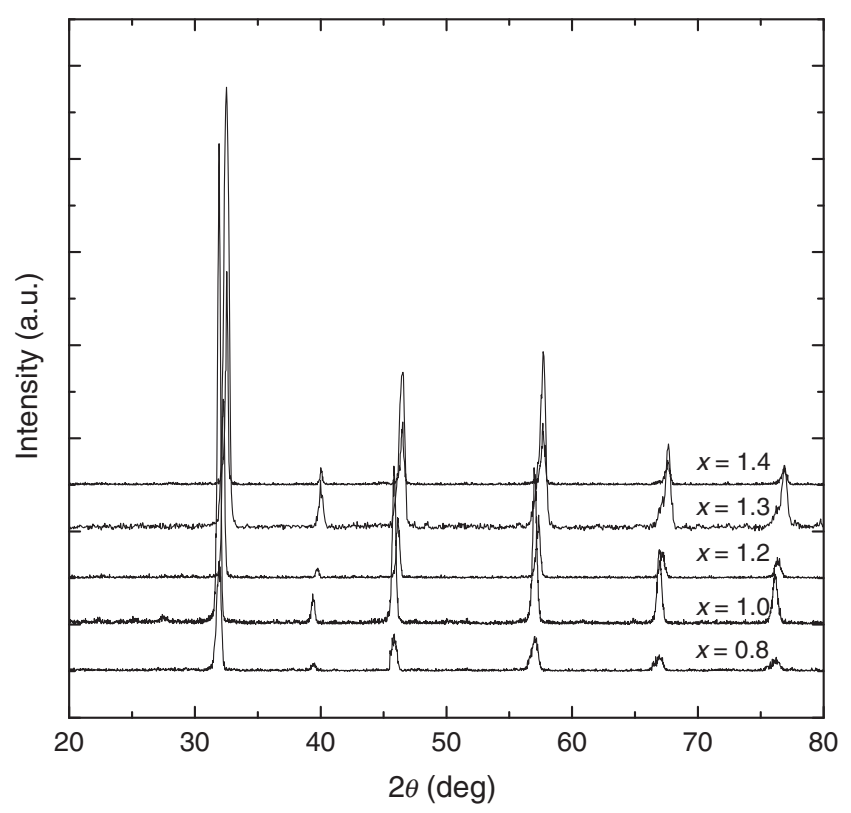

Figure 1. $\mathrm{X}$-ray diffraction patterns of $\mathrm{Sr}_{2} \mathrm{Fe}_{x} \mathrm{Mo}_{2-x} \mathrm{O}_{6}(0.8 \leq$ $x \leq 1.4$ ) double perovskites recorded at room temperature. valence disproportion as observed in double perovskites. ${ }^{18-20}$ Further, it can be noted from table 1 that the structural transition from tetragonal to cubic lattice occurs at around $x=1.2$ in SFMO ${ }^{21}$ The tolerance factor of SFMO double perovskite is given by

$$
t=\frac{r_{\mathrm{Sr}}+r_{\mathrm{O}}}{\sqrt{2}\left(\frac{r_{\mathrm{Fe}} x}{2}+\frac{r_{\mathrm{Mo}}(2-x)}{2}+r_{\mathrm{O}}\right)},
$$

where $r_{\mathrm{Sr}}, r_{\mathrm{Fe}}, r_{\mathrm{Mo}}$ and $r_{\mathrm{O}}$ are the ionic radii of $\mathrm{Sr}, \mathrm{Fe}, \mathrm{Mo}$ and $\mathrm{O}$ ions, respectively. The tolerance factor $(t)$ of SFMO compounds was calculated by employing equation (1) and the values are included in table 1 . It is found from table 1 that the deviation of tolerance factor from unity in SFMO samples increases with the increase of Fe content, indicating the increase of distortion from ideal double perovskite structure with Fe content.

The SEM photograph of SFMO sample is shown in figure $2 \mathrm{a}-\mathrm{e}$. It is observed from these figures that the porosity is present in the samples. The pore size changes from sample to sample. The pore size is very small and material is closely packed with fewer voids for composition $x=1.3$. It is slightly larger for rest of the compositions in SFMO samples.

Figure 3 shows FTIR spectra of the $\mathrm{Sr}_{2} \mathrm{Fe}_{x} \mathrm{Mo}_{2-x} \mathrm{O}_{6}(x=$ $0.8,1.0,1.2,1.3$ and 1.4) samples in the spectral wavenumber range of 400 and $1000 \mathrm{~cm}^{-1}$. Three characteristic absorption bands between 400 and $860 \mathrm{~cm}^{-1}$ are usually used to identify the perovskite phase formation. ${ }^{12}$ In the present study, FTIR spectra of the SFMO samples show three absorption bands corresponding to $\mathrm{Fe}-\mathrm{O}$ and $\mathrm{Mo}-\mathrm{O}$ vibrations, namely, strong bands in the high-wavenumber range $\sim 809$ and $858 \mathrm{~cm}^{-1}$ with associated with the Mo-O symmetric stretching mode of $\mathrm{MoO}_{6}$ octahedra; broad band at $\sim 630 \mathrm{~cm}^{-1}$ and weak band at $\sim 702 \mathrm{~cm}^{-1}$ assigned to the antisymmetric stretching mode of the $\mathrm{MoO}_{6}$ octahedra due to the higher charge of this cation. ${ }^{13}$ The weak absorption band obtained at about $422 \mathrm{~cm}^{-1}$ is ascribed to $\mathrm{Fe}-\mathrm{O}$ vibration absorption of $\mathrm{FeO}_{6}$ octahedra. In SFMO double perovskite samples, the highly charged Mo cation octahedra $\left(\mathrm{MoO}_{6}\right)$ acts as independent group, the vibration spectrum therefore arises from such $\mathrm{MoO}_{6}$ octahedra. Mo-O symmetric stretching mode of $\mathrm{MoO}_{6}$ octahedra at about 809 and $858 \mathrm{~cm}^{-1}$ is usually an infrared inactive vibration, but in a double perovskite, both $\mathrm{Fe}$ and Mo ions exist in Fe and Mo sites and it becomes partially allowed due to lowering of site symmetry. ${ }^{13}$

Table 1. Values of lattice parameters ( $a$ and $c$ ), unit cell volume $(V)$, tolerance factor $(t)$ and $g$-factor of the $\operatorname{Sr}_{2} \mathrm{Fe}_{x} \mathrm{Mo}_{2-x} \mathrm{O}_{6}(0.8 \leq x \leq$ 1.4) double perovskites.

\begin{tabular}{|c|c|c|c|c|c|}
\hline Composition $(x)$ & 0.8 & 1.0 & 1.2 & 1.3 & 1.4 \\
\hline Lattice parameter $(a(\AA))$ & 5.574 & 5.567 & 5.563 & 7.839 & 7.831 \\
\hline Lattice parameter $(c(\AA))$ & 7.909 & 7.898 & 7.889 & - & - \\
\hline Unit cell volume $\left(V\left(\AA^{3}\right)\right)$ & 491.46 & 489.54 & 488.28 & 481.70 & 480.23 \\
\hline Tolerance factor $(t)$ & 0.9923 & 0.9906 & 0.9889 & 0.988 & 0.9872 \\
\hline$g$-Factor & - & 2.045 & 2.032 & 2.050 & 2.024 \\
\hline
\end{tabular}



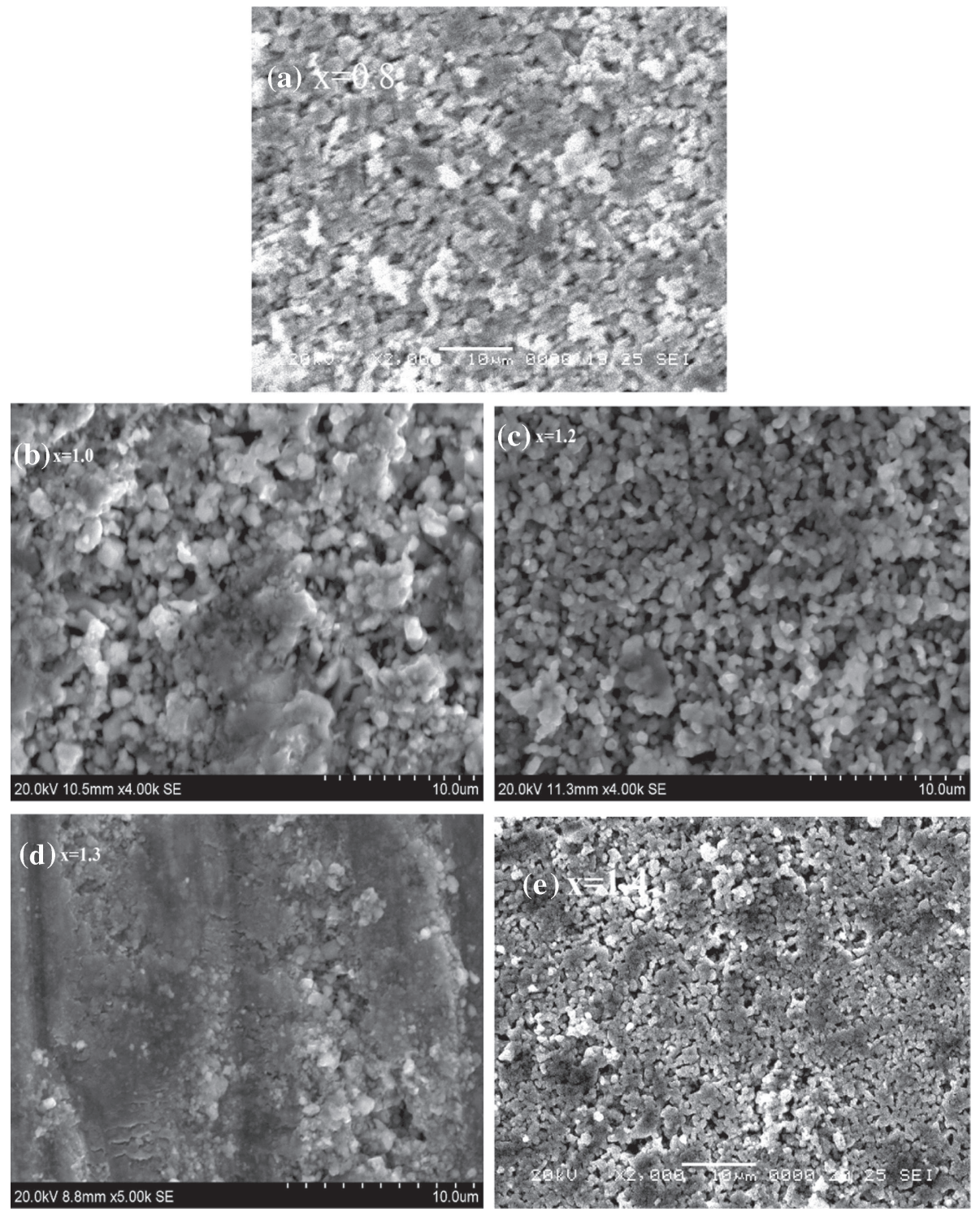

Figure 2. SEM micrographs of $\mathrm{Sr}_{2} \mathrm{Fe}_{x} \mathrm{Mo}_{2-x} \mathrm{O}_{6}$ double perovskites for Fe content (a) $x=$ 0.8 , (b) $x=1.0$, (c) $x=1.2$, (d) $x=1.3$ and (e) $x=1.4$.

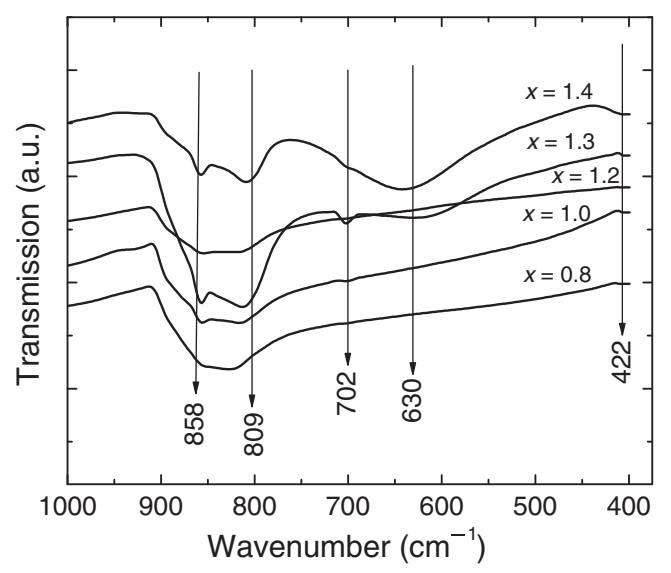

Figure 3. FTIR spectra of $\mathrm{Sr}_{2} \mathrm{Fe}_{x} \mathrm{Mo}_{2-x} \mathrm{O}_{6}(x=0.8,1.0,1.2$, 1.3 and 1.4) samples.
The bands obtained in the present study confirm the formation of perovskite phase.

ESR spectra of $\mathrm{Sr}_{2} \mathrm{Fe}_{x} \mathrm{Mo}_{2-x} \mathrm{O}_{6}(x=1.0,1.2,1.3$ and 1.4) samples taken at room temperature are shown in figure 4a-d. All the figures show a similar spectrum. It is observed from spectra that a peak is resolved at around $H=310$ $\mathrm{mT}$ for all samples. The value of $g$-factor of SFMO samples were evaluated using $g=h v / \beta H$, where $h$ is Planck's constant $\left(6.625 \times 10^{-34} \mathrm{~J} \mathrm{~s}\right), v$ the frequency of magnetic field, $\beta$ the Bohr magneton $\left(9.274 \times 10^{-24} \mathrm{~J} \mathrm{Tesla}^{-1}\right), H$ the applied magnetic field. The value of $g$-factor thus obtained is included in table 1 . It is found from table 1 that the value of $g$-factor is close to 2.00, indicating $\mathrm{Fe}$ is in $3+$ state in SFMO samples. Therefore, the ESR spectra of SFMO samples obtained in this study correspond to the localized $3 \mathrm{~d}^{5}$ Fe cores in the band picture as reported by Kobayashi et al. ${ }^{1}$ This rules out the possibility of assigning the observed spin 


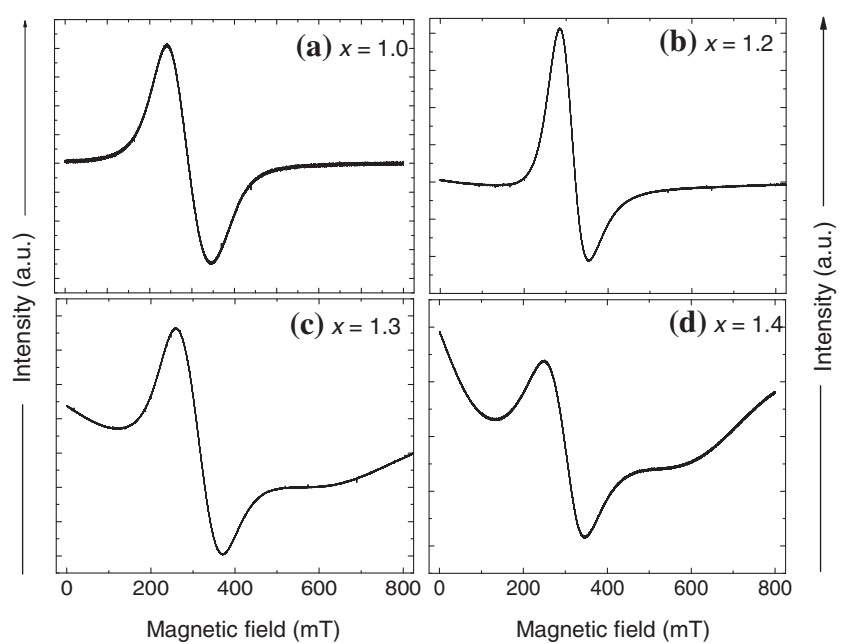

Figure 4. ESR spectrum of $\mathrm{Sr}_{2} \mathrm{Fe}_{x} \mathrm{Mo}_{2-x} \mathrm{O}_{6}$ samples for (a) $x=$ 1.0 , (b) $x=1.2$, (c) $x=1.3$ and (d) $x=1.4$.

resonance to localized $\mathrm{Fe}^{2+}$ in SFMO samples. Because its ground state in octahedral environment is a triplet with an expected $g$-factor about 3.4. On the other hand, if $\mathrm{Fe}^{2+}$ ions were also present, their short relaxation time would render their ESR line undetectable as in the case of $\mathrm{FeO}$. If this was the case, the $\mathrm{Fe}^{2+}-\mathrm{Fe}^{3+}$ coupling would induce a $g$-shift to the $\mathrm{Fe}^{3+}$ ESR line. ${ }^{14}$ Hence, in the present study, it can be concluded that SFMO samples contain $\mathrm{Fe}^{3+}$ ions only since the observed $g$-value remains constant in the whole composition range. Further, the small distortion observed in the shape of spectrum for the samples $x>1.2$ in figure $4 \mathrm{c}$ and $\mathrm{d}$ might be attributed to structural phase change from tetragonal to cubic at $x=1.2$ in conformity with results obtained from XRD studies.

\subsection{Thermal expansion}

The thermal expansion characteristics $\left(\Delta L / L_{0}\right)$ of $\mathrm{Sr}_{2} \mathrm{Fe}_{x} \mathrm{Mo}_{2-x} \mathrm{O}_{6}(x=0.8,1.0,1.2,1.3$ and 1.4) in the temperature range from 40 to $400^{\circ} \mathrm{C}$ obtained using dilatometer are shown in figure 5. The thermal expansion depends on the electrostatic forces within the lattice, which depend on the concentration of positive and negative charges and their distances within the lattice. ${ }^{22}$ The thermal expansion of a solid is characterized by the coefficient of thermal expansion $(\alpha)$ caused by the thermal lattice vibrations given by

$$
\alpha=\frac{\mathrm{d}}{\mathrm{d} T}\left(\frac{\Delta L}{L_{\mathrm{o}}}\right)=\frac{L_{1}-L_{\mathrm{o}}}{L_{\mathrm{o}}\left(T_{1}-T_{\mathrm{o}}\right)},
$$

where $L_{\mathrm{o}}$ and $L_{1}$ are the lengths of sample at temperature $T_{\mathrm{o}}$ and $T_{1}$, respectively.

The experimental data of thermal expansion $\left(\Delta L / L_{\mathrm{o}}\right)$ as a function of temperature $(T)$ of SFMO samples in the present study can be fitted to a polynomial of degree 2 as

$$
\frac{\Delta L}{L_{\mathrm{o}}}=A+B T+C T^{2},
$$

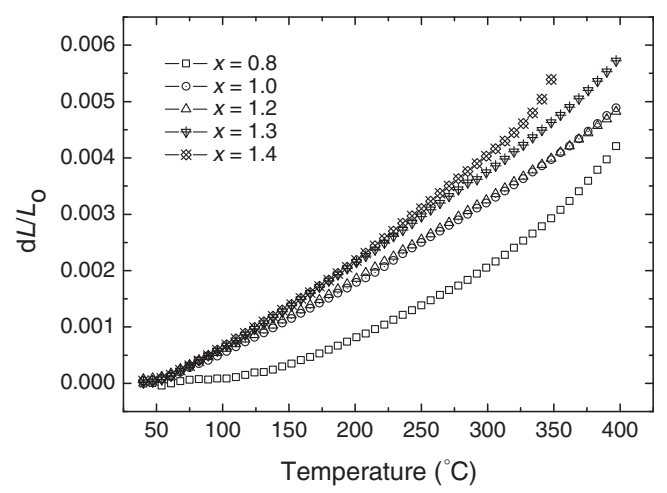

Figure 5. Variation of $\Delta L / L_{\mathrm{O}}$ as a function of temperature of $\mathrm{Sr}_{2} \mathrm{Fe}_{x} \mathrm{Mo}_{2-x} \mathrm{O}_{6}(0.8 \leq x \leq 1.4)$ double perovskites.

where $A, B$ and $C$ are the constants and given in table 2 for all the samples. The value of $\alpha$ then can be determined using the first derivative of equation (3) with respect to temperature as

$$
\alpha=\frac{\mathrm{d}}{\mathrm{d} T}\left(\frac{\Delta L}{L_{\mathrm{o}}}\right)=B+2 C T,
$$

Equation (4) shows that the value of $\alpha$ at any temperature can be obtained using constants $B$ and $C$.

The average value of coefficient of thermal expansion $(\bar{\alpha})$ in the temperature range from $T_{\mathrm{o}}$ to $T_{1}$ can be determined using the relation

$$
\bar{\alpha}=\frac{1}{T_{1}-T_{\mathrm{o}}} \int_{T_{\mathrm{o}}}^{T_{1}}(B+2 C T) \mathrm{d} T .
$$

Thus, the value of $\bar{\alpha}$ was evaluated in different temperature ranges namely $40-100,40-200,40-300$ and $40-400^{\circ} \mathrm{C}$ for all SFMO materials and are given in table 2 . The plot of $\bar{\alpha}$ $v s$. Fe composition of SFMO in the temperature ranges 40 300 and $40-400^{\circ} \mathrm{C}$ is shown in figure 6 and it is observed that the value of $\bar{\alpha}$ increases with the Fe content and temperature. Falcon $e t a l^{23}$ investigated the oxidation profiles of $\mathrm{Sr}_{2} \mathrm{FeMoO}_{6-\delta}$ oxide, results showed that oxygen was relatively easily incorporated into the perovskite structure. Increase in the oxygen vacancy concentration leads to oxygen permeation and lattice expansion which becomes much more pronounced. ${ }^{24}$ Therefore, in the present study increase in the value of $\bar{\alpha}$ of SFMO samples with the increase in temperature may be attributed to increase in concentration of oxygen vacancy. Zhang et $a l^{11}$ have reported that the value of $\bar{\alpha}$ of $\mathrm{Sr}_{2} \mathrm{FeMoO}_{6-\delta}$ in the temperature range $30-1000^{\circ} \mathrm{C}$ is $13.9 \times 10^{-6}{ }^{\circ} \mathrm{C}^{-1}$. The value of $\bar{\alpha}$ of $\mathrm{Sr}_{2} \mathrm{FeMoO}_{6}$ obtained in the present study in the temperature ranges $40-400{ }^{\circ} \mathrm{C}^{-1}$ is $13.8 \times 10^{-6}{ }^{\circ} \mathrm{C}^{-1}$ is very much in agreement with that reported by Zhang et al. ${ }^{11}$ It is also found from figure 6 that the value of $\bar{\alpha}$ increases with the increase in Fe content. This increase in $\bar{\alpha}$ may be attributed to substitution of larger ionic size of $\mathrm{Fe}^{3+}(0.645 \AA)$ at smaller ionic size of $\mathrm{Mo}^{5+}$ site $(0.61 \AA)$. Further, it is to be noted that the average value of coefficient of thermal expansion of $\mathrm{Sr}_{2} \mathrm{Fe}_{0.8} \mathrm{Mo}_{1.2} \mathrm{O}_{6}$ is found to be 
Table 2. Values of constants $A, B, C$ of equation (3), and average value of coefficient of thermal expansion $(\bar{\alpha})$ in different temperature ranges for $\mathrm{Sr}_{2} \mathrm{Fe}_{x} \mathrm{Mo}_{2-x} \mathrm{O}_{6}(0.8 \leq x \leq 1.4)$ double perovskites.

\begin{tabular}{|c|c|c|c|c|c|c|c|}
\hline \multirow[b]{2}{*}{ Composition $(x)$} & \multirow[b]{2}{*}{$A$} & \multirow[b]{2}{*}{$B$} & \multirow[b]{2}{*}{$C$} & \multicolumn{4}{|c|}{$\bar{\alpha}\left(\times 10^{-6{ }^{\circ}} \mathrm{C}^{-1}\right)$} \\
\hline & & & & $40-100^{\circ} \mathrm{C}$ & $40-200^{\circ} \mathrm{C}$ & $40-300^{\circ} \mathrm{C}$ & $40-400^{\circ} \mathrm{C}$ \\
\hline 0.8 & $0.99 \times 10^{-4}$ & $-3.41 \times 10^{-6}$ & $3.37 \times 10^{-8}$ & 1.31 & 4.67 & 8.01 & 11.41 \\
\hline 1.0 & $-4.31 \times 10^{-4}$ & $8.70 \times 10^{-6}$ & $1.16 \times 10^{-8}$ & 10.32 & 11.48 & 12.29 & 13.80 \\
\hline 1.2 & $-4.44 \times 10^{-4}$ & $9.61 \times 10^{-6}$ & $0.91 \times 10^{-8}$ & 10.88 & 11.79 & 12.72 & 14.19 \\
\hline 1.3 & $-5.81 \times 10^{-4}$ & $11.33 \times 10^{-6}$ & $1.08 \times 10^{-8}$ & 12.83 & 13.92 & 15.00 & 16.08 \\
\hline 1.4 & $-4.45 \times 10^{-4}$ & $8.95 \times 10^{-6}$ & $2.06 \times 10^{-8}$ & 11.83 & 13.89 & 15.95 & - \\
\hline
\end{tabular}

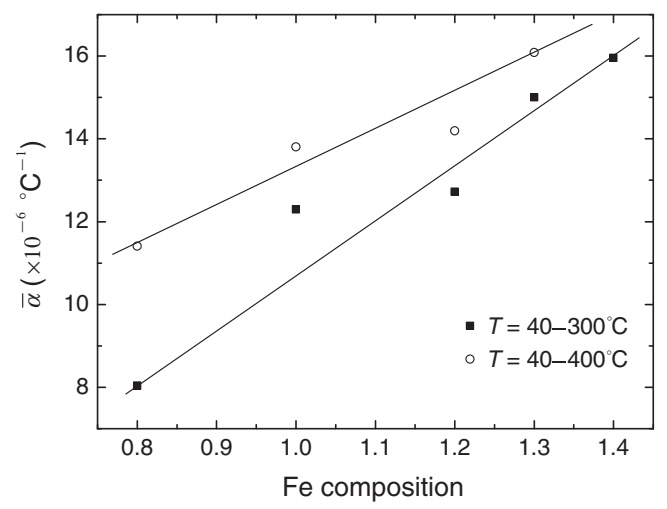

Figure 6. Variation of average value of coefficient of thermal expansion $(\bar{\alpha})$ with $\mathrm{Fe}$ composition at different temperature ranges $40-300$ and $40-400^{\circ} \mathrm{C}$ of SFMO samples.

$1.31 \times 10^{-6}{ }^{\circ} \mathrm{C}^{-1}$ in the temperature range $40-100^{\circ} \mathrm{C}$ makes this material in fuel cell applications as anodes.

It is observed from table 1 and figure 6 that the value of unit cell parameters decrease and the value of $\bar{\alpha}$ increases with the increase in $\mathrm{Fe}$ content, indicating an inverse relation between the value of $\bar{\alpha}$ and unit cell parameters in accordance with the following Gruneisen's relation: ${ }^{22,25}$

$$
\alpha_{\mathrm{v}}=\frac{\gamma_{\mathrm{G}} C_{\mathrm{v}} \chi}{V},
$$

where $\alpha_{\mathrm{v}}$ is the coefficient of volume thermal expansion, $\gamma_{\mathrm{G}}$ Gruneisen's constant, $C_{\mathrm{v}}$ the heat capacity at constant volume, $\chi$ the compressibility, and $V$ the volume of the unit cell.

\section{Conclusions}

(1) It has been found that the lattice parameters and unit cell volume decreases with the increase of Fe content in SFMO samples.

(2) A structural transition from tetragonal to cubic at around $x=1.2$ is observed in SFMO samples.

(3) The FTIR spectra of SFMO showed three characteristic absorption bands in the range of $860-400 \mathrm{~cm}^{-1}$, indicating the formation of perovskite structure.

(4) ESR results of the samples show that the iron is in $\mathrm{Fe}^{3+}$ state in SFMO samples.
(5) The results of thermal expansion showed that the average value of coefficient of thermal expansion $(\bar{\alpha})$ increases with the increase in temperature or $\mathrm{Fe}$ content in SFMO samples.

\section{Acknowledgements}

One of the authors (GB) wish to thank DST for providing financial assistance to carry out this work through a project OU-DST-PURSE-Scheme No. A.60. We express our gratitude to the Head, Department of Physics, Osmania University and the Head, Department of Physics and Principal, Nizam College, Osmania University, Hyderabad, for their encouragement. We also thank Prof V Seshubai, University of Hyderabad, for providing ESR measurements.

\section{References}

1. Kobayashi K I, Kimura T, Sawada H, Terakura K and Tokura Y 1998 Nature (Lond.) 395677

2. Ray S, Middey S, Jana S, Banerjee A, Sanyal P, Rawat R, Gregoratti L and Sarma D D 2011 J. EPL 9447007

3. Lu M F, Wang J P, Liu J F, Song W, Hao X F, Zhou D F, Liu X J, Wu Z J and Meng J 2007 J. Alloys Compd. 428214

4. Gaur A, Varma G D and Singh H K 2008 J. Alloys Compd. 460 581

5. Bufaiçal L, Adriano C, Lora-Serrano R, Duque J G S, Mendonça-Ferreira L, Rojas-Ayala C, Baggio-Saitovitch E, Bittar E M and Pagliuso P G 2014 J. Solid State Chem. 21223

6. Feng X M, Rao G H, Liu G Y, Yang H F, Liu W F, Ouyang Z W and Liang J K 2004 Physica B 34421

7. Markandeya Y, Suresh K and Bhikshamaiah G 2011 J. Alloys Compd. $\mathbf{5 0 9} 9598$

8. Markandeya Y, Saritha D, Vithal M, Singh A K and Bhikshamaiah G 2011 J. Alloys Compd. 5095195

9. Huo G, Ren X, Qian L, Zhang N, Liu S and Yan X 2013 J. Magn. Magn. Mater. 343119

10. Mohamed Musa Saad H-E 2012 Physica B 4072512

11. Zhang L, Zhou Q, He Q and He T 2010 J. Power Sources 195 6356

12. Mostafa M F, Ata-Allah S S, Youssef A A A and Refai H S 2008 J. Magn. Magn. Mater. 320344

13. Lavat A E and Baran E J 2003 Vib. Spectrosc. 32167 
14. Gulley J E and Jaccarino V 1972 Phys. Rev. B 658

15. Kapusta Cz, Riedi P C, Zajac D, Sikora M, De Teresa J M, Morellon L and Ibarra M R 2002 J. Magn. Magn. Mater. 242245701

16. Kim S B, Lee B W and Kim C S 2002 J. Magn. Magn. Mater. 242-245 747

17. Xue J, Shen Y and He T 2011 J. Power Sources 1963729

18. Topfer J and Goodenough J B 1997 Chem. Mater. 91467

19. van Roosmalen J A M, van Vlaanderen P, Cordfunke E H P, Ijdo W L and Ijdo D J W 1995 J. Solid State Chem. 114516

20. Takeda Y, Kanno K, Takada T, Yamamoto O, Takano M, Nakayama N and Bando Y 1986 J. Solid State Chem. 63237
21. Yoshida K, Keuchi S I, Shimizu H, Okayasu S and Suzuki T 2011 J. Phys. Soc. Jpn. 80044716

22. Prasanth Kumar V, Reddy Y S, Kistaiah P, Prasad G and Vishnuvardhan Reddy C 2008 Mater. Chem. Phys. 112 711

23. Falcon H, Barbero J A, Araujo G, Casais M T, MartinezLope M J, Alonso J A and Fierro J L G 2004 Appl. Catal. B-Environ. 5337

24. Onuma S, Yashiro K, Miyoshi S, Kaimai A, Matsumoto H, Nigara Y, Kawada T, Mizusaki J, Kawamura K, Sakai N and Yokokawa H 2004 Solid State Ion. 174287

25. Eastabrook J N 1957 Philos. Mag. 21421 